NASA/TM-1999-209721

ARL-TR-2120
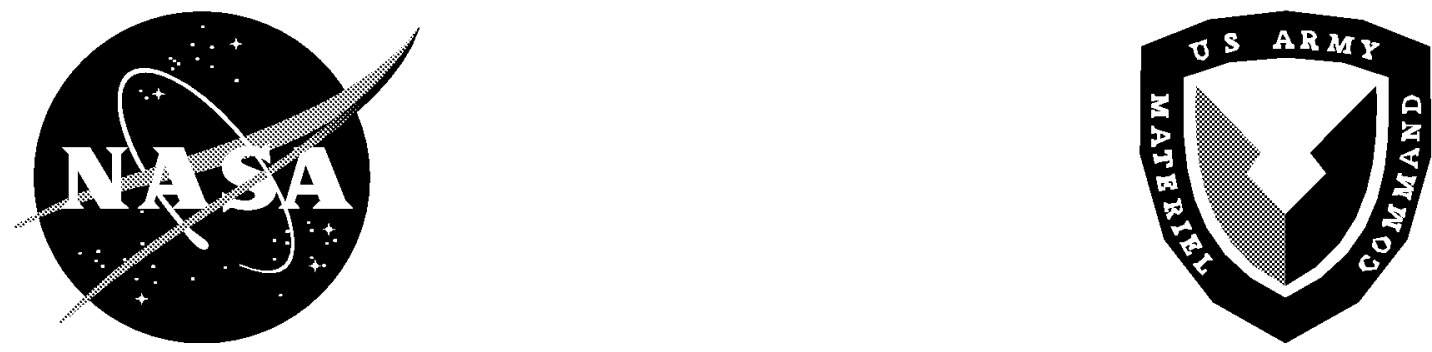

\title{
Single Axis Piezoceramic Gimbal
}

\author{
Garnett C. Horner
}

Langley Research Center, Hampton, Virginia

Barmac K. Taleghani

U. S. Army Research Laboratory

Vehicle Technology Directorate

Langley Research Center, Hampton, Virginia 


\section{The NASA STI Program Office ... in Profile}

Since its founding, NASA has been dedicated to the advancement of aeronautics and space science. The NASA Scientific and Technical Information (STI) Program Office plays a key part in helping NASA maintain this important role.

The NASA STI Program Office is operated by Langley Research Center, the lead center for NASA's scientific and technical information. The NASA STI Program Office provides access to the NASA STI Database, the largest collection of aeronautical and space science STI in the world. The Program Office is also NASA's institutional mechanism for disseminating the results of its research and development activities. These results are published by NASA in the NASA STI Report Series, which includes the following report types:

- TECHNICAL PUBLICATION. Reports of completed research or a major significant phase of research that present the results of NASA programs and include extensive data or theoretical analysis. Includes compilations of significant scientific and technical data and information deemed to be of continuing reference value. NASA counterpart of peer-reviewed formal professional papers, but having less stringent limitations on manuscript length and extent of graphic presentations.

- TECHNICAL MEMORANDUM. Scientific and technical findings that are preliminary or of specialized interest, e.g., quick release reports, working papers, and bibliographies that contain minimal annotation. Does not contain extensive analysis.

- CONTRACTOR REPORT. Scientific and technical findings by NASA-sponsored contractors and grantees.
- CONFERENCE PUBLICATION. Collected papers from scientific and technical conferences, symposia, seminars, or other meetings sponsored or co-sponsored by NASA.

- SPECIAL PUBLICATION. Scientific, technical, or historical information from NASA programs, projects, and missions, often concerned with subjects having substantial public interest.

- TECHNICAL TRANSLATION. Englishlanguage translations of foreign scientific and technical material pertinent to NASA's mission.

Specialized services that complement the STI Program Office's diverse offerings include creating custom thesauri, building customized databases, organizing and publishing research results ... even providing videos.

For more information about the NASA STI Program Office, see the following:

- Access the NASA STI Program Home Page at http://Www.sti.nasa.gov

- E-mail your question via the Internet to help@sti.nasa.gov

- Fax your question to the NASA STI Help Desk at (301) 621-0134

- $\quad$ Phone the NASA STI Help Desk at (301) 621-0390

- Write to: NASA STI Help Desk NASA Center for AeroSpace Information 7121 Standard Drive Hanover, MD 21076-1320 
NASA/TM-1999-209721

ARL-TR-2120
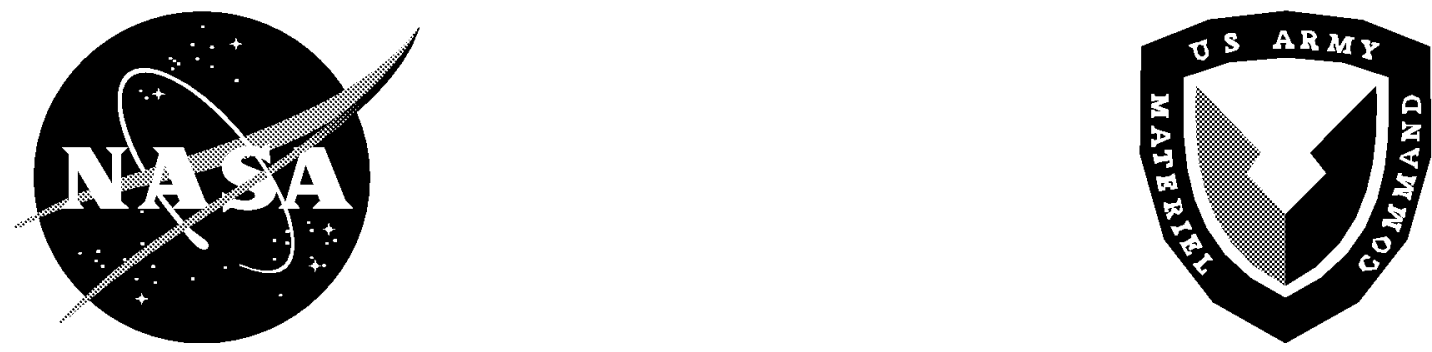

\section{Single Axis Piezoceramic Gimbal}

Garnett C. Horner

Langley Research Center, Hampton, Virginia

Barmac K. Taleghani

U. S. Army Research Laboratory

Vehicle Technology Directorate

Langley Research Center, Hampton, Virginia

National Aeronautics and

Space Administration

Langley Research Center

Hampton, Virginia 23681-2199 
The use of trademarks or names of manufacturers in the report is for accurate reporting and does not constitute an official endorsement, either expressed or implied, of such products or manufacturers by the National Aeronautics and Space Administration or the U.S. Army.

Available from:

NASA Center for AeroSpace Information (CASI)

7121 Standard Drive

Hanover, MD 21076-1320

(301) 621-0390
National Technical Information Service (NTIS)

5285 Port Royal Road

Springfield, VA 22161-2171

(703) 605-6000 


\title{
Single Axis Piezoceramic Gimbal
}

\author{
Garnett Horner ${ }^{\mathrm{a}}$ and Barmac Taleghani ${ }^{\mathrm{b}}$ \\ ${ }^{a}$ NASA Langley Research Center, MS 230, Hampton VA 23681 \\ ${ }^{\mathrm{b}}$ U.S. Army Vehicle Technology Directorate, Hampton, VA
}

\begin{abstract}
This paper describes the fabrication, testing, and analysis of a single axis piezoceramic gimbal. The fabrication process consists of pre-stressing a piezoceramic wafer using a high-temperature thermoplastic polyimide and a metal foil. The differential thermal expansion between the ceramic and metal induces a curvature. The piezoceramic is mounted on a support mechanism and a mirror is attached to the piezoceramic. A finite element analysis of the gimbal is described and the predicted gimbal angle versus applied voltage is compared to experimental results.
\end{abstract}

Keywords: actuator, gimbal, piezoceramic, scanner

\section{INTRODUCTION}

The development of a new processing technique called THUNDER (THin-layer composite UNimorph piezoelectric Driver and $\mathrm{E}$ EnsoR) technology ${ }^{1}$ enables new types of actuator concepts. The THUNDER technology produces a curved piezoceramic by combining a flat piezoceramic wafer with a thin metal foil using a polyimide thermoplastic called LARC ${ }^{\text {TM }}$ SI as an adhesive. Using a thin film of the LARCTM-SI between the metal foil and the piezoceramic, the three layers are held together under pressure while they are heated above the melting point of the LARCTM-SI to produce a composite. As the composite is cooled below the melting point of the LARCTM-SI, the foil is bonded to the piezoceramic. Upon further cooling, the miss-match in coefficient of thermal expansion between the metal foil and the ceramic causes a compressive prestress in the piezoceramic at room temperature.

This curved composite using THUNDER technology produces large amplitudes of motion when a voltage field is applied across the piezoceramic. Depending upon the polarity of the applied field, the radius of curvature of the composite will either increase or decrease. When mechanisms are coupled to the composite along the axis of symmetry, translational motion is achieved as the applied field is varied.

The purpose of this paper is to investigate an approach for producing rotational motion using THUNDER technology. The resulting piezoelectric gimbal does not have any moving parts. This piezoceramic gimbal would be used with a small mirror to produce a scanner for applications to sampling or surveillance-type instruments on spacecraft.

\section{THE CONCEPT}

The concept is to transform the linear motion of the THUNDER technology composite into rotational motion. We note that the radius of curvature of a single THUNDER technology piezoceramic composite changes with applied voltage field. This is shown schematically in Figure 1. 


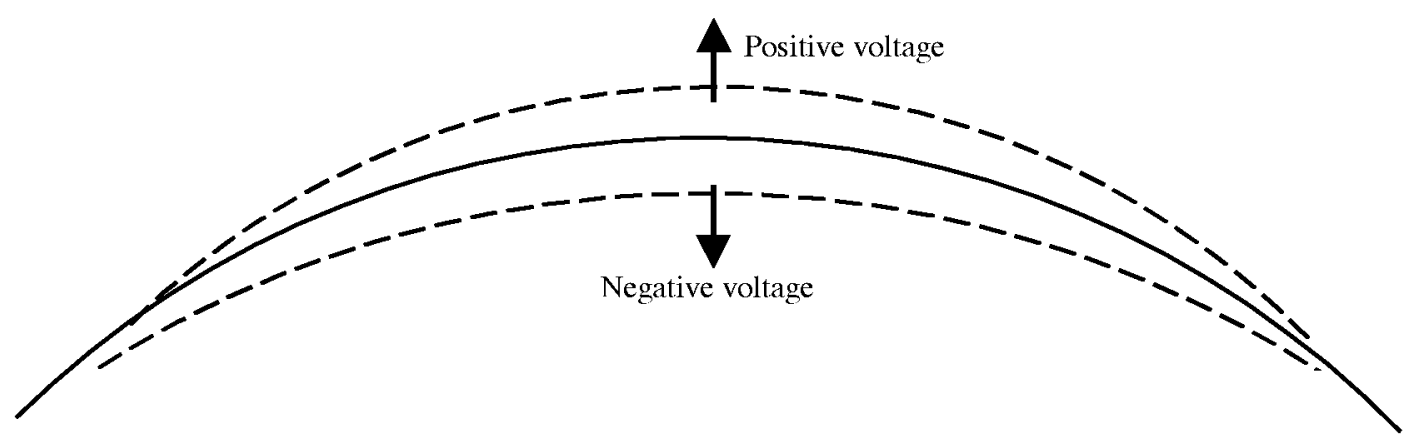

Figure 1: Changes in curvature of THUNDER wafer with free-free boundary conditions

We suggest that if the increased and decreased changes in curvature could be combined into a single composite, the axis of symmetry would rotate instead of translating. It is this angular motion that could be used as a gimbal actuator for a device such as a scanning mirror.

As shown in Figure 2, starting with an unelectroded piezoceramic wafer such as PZT-5A, an identical electrode pattern is screened onto both sides of the ceramic. The screening process uses a mask and silver paste to apply the electrode pattern. There are two electrode surfaces with the opposite sides having identical electrode pattern. These four electrode surfaces constitute two independent piezoceramic actuators. Since the electrode surfaces are equal in area, there are two separate actuators on a single piezoceramic wafer.

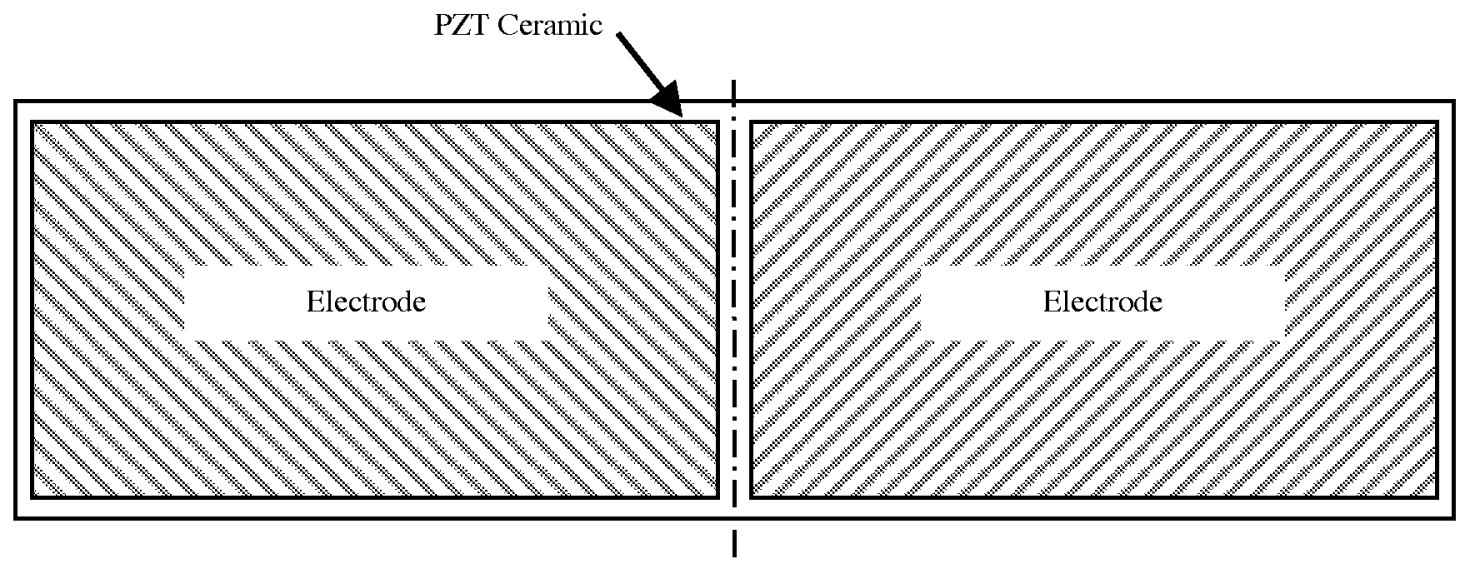

Figure 2: Electrode pattern

The process for fabrication of this gimbal is similar to that used to process THUNDER technology piezoceramics. A .008" thick electroded PZT-5A ceramic is bonded to a .002" thick sheet of stainless steel using a polyimide thermoplastic. The bonding or consolidation of these pieces is done in an autoclave at elevated temperature and pressure. As the autoclave is cooled, the thermoplastic adhesive bonds but since there is a mismatch in the coefficient of thermal expansion (CTE) between the PZT ceramic and the stainless steel, the consolidated assembly is curved due to different thermal strains in the ceramic and metal. A consolidated assembly with electrical leads attached is shown in Figure 3. 


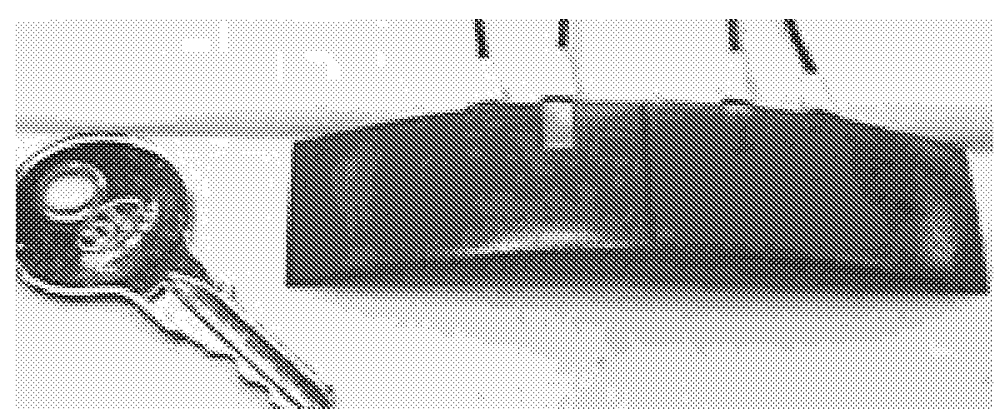

Figure 3: Consolidated, pre-stressed piezo-metal composite

As shown in Figure 4, after consolidation, the curved piezo-metal composite is bonded to a polypropylene mount and a mirror is bonded in the center. The polypropylene has good fatigue properties, which allows the mount to be made from a single sheet of the polypropylene. A mechanism was formed by making partial cuts in the material along the desired hinge axis. Next, each half of the ceramic is poled in the same direction by applying 500 volts D.C.

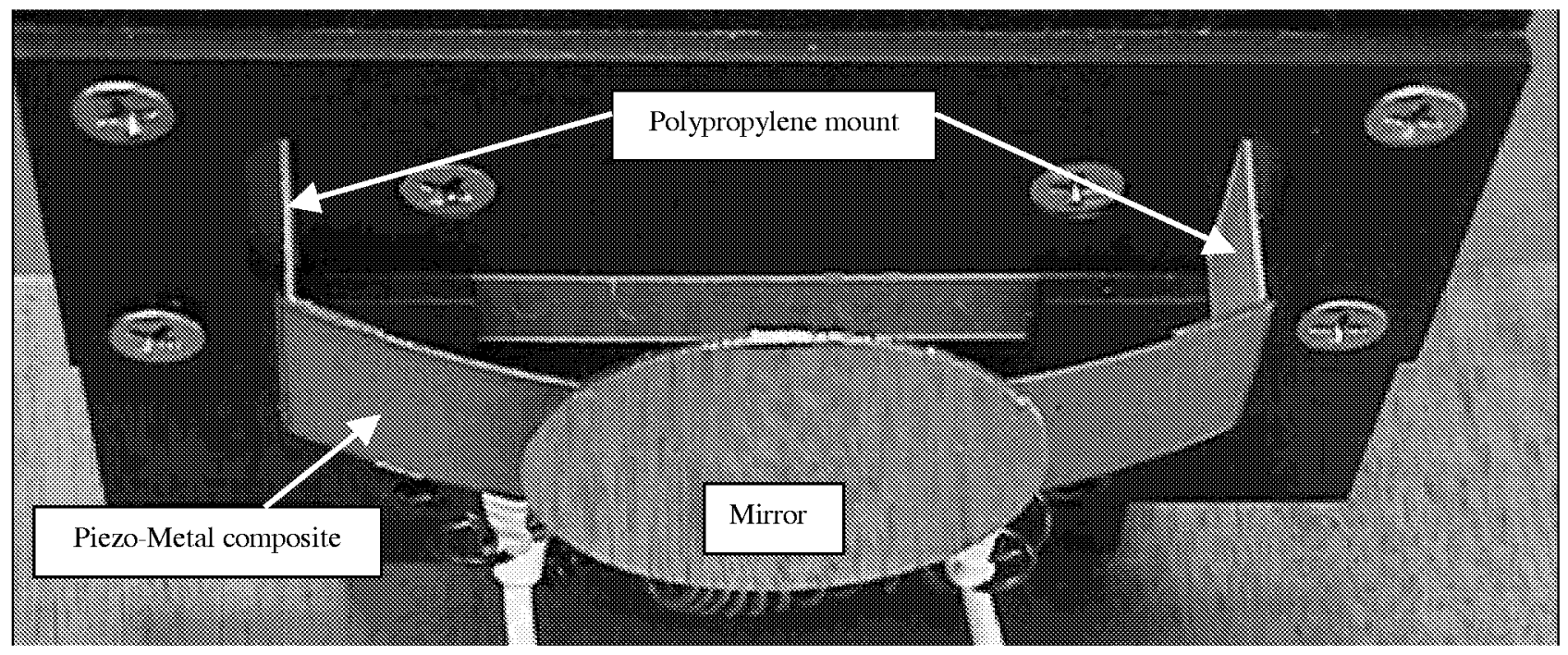

Figure 4: Piezo-metal composite with mirror

The piezoceramic halves are connected such that the positive side of one half is connected to the negative side of the other half. The negative side of the first half and the positive side of the second half are connected to an amplified voltage source. In this way, one amplifier can be used to drive the two halves in the opposite sense. That is, as one half is becoming more domed and shorter, the other half is becoming less domed and longer. This combination of motions causes the mid-point between the two piezoceramics to rotate. This mid-point rotation can be used to command and control the mirror gimbal angle.

\section{TEST RESULTS}

The gimbal angle was measured as a function of the applied voltage using the setup shown in Figure 5. The light source is reflected off the mirror onto a detector that measures a translational distance $s$, along the detector. Knowing the distance $r$, from the mirror to the detector and using a small angle approximation, the gimbal angle is simply $s /(2 r)$, that is, half the reflected beam angle. 


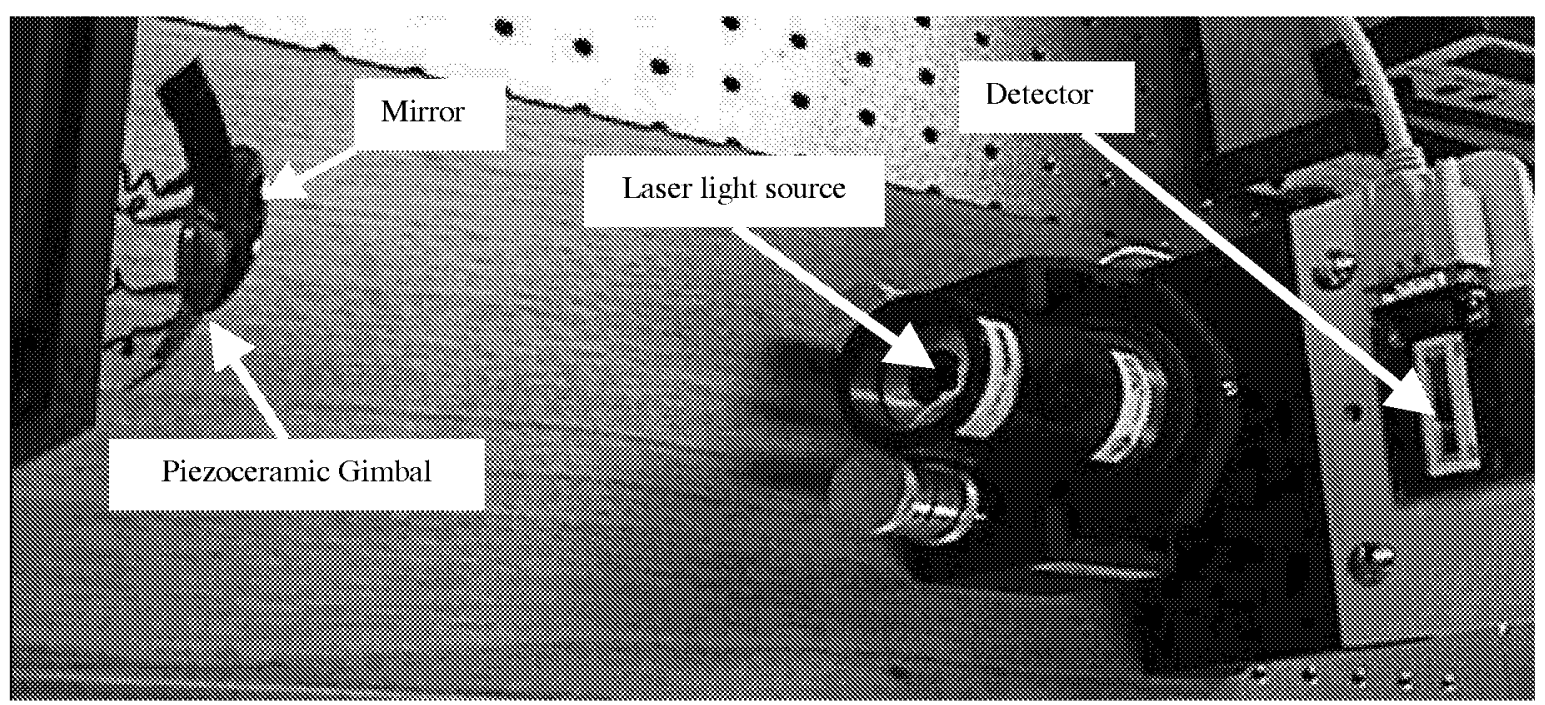

Figure 5: Experimental set-up for measuring gimbal angle as a function of driving voltage

Using a data acquisition system, the voltage applied to the piezoceramic and the corresponding location of the beam on the detector are stored for several cycles. The voltage was varied between \pm 200 volts at nearly quasi-static conditions. The results of this test are shown in Figure 6. As seen from the hysteresis, the composite piezoceramic gimbal is non-linear and dissipative. This is likely due to several factors. First, the piezoceramic is a sintered material which will likely exhibit micro-level motion between adjacent particles. Second, the polymer used to bond the metal foil to the piezoceramic could have some dissipation. From the data, the gimbal angle varies between - 0.64 to 1.18 degrees. Nominally, this is \pm 0.91 degrees.

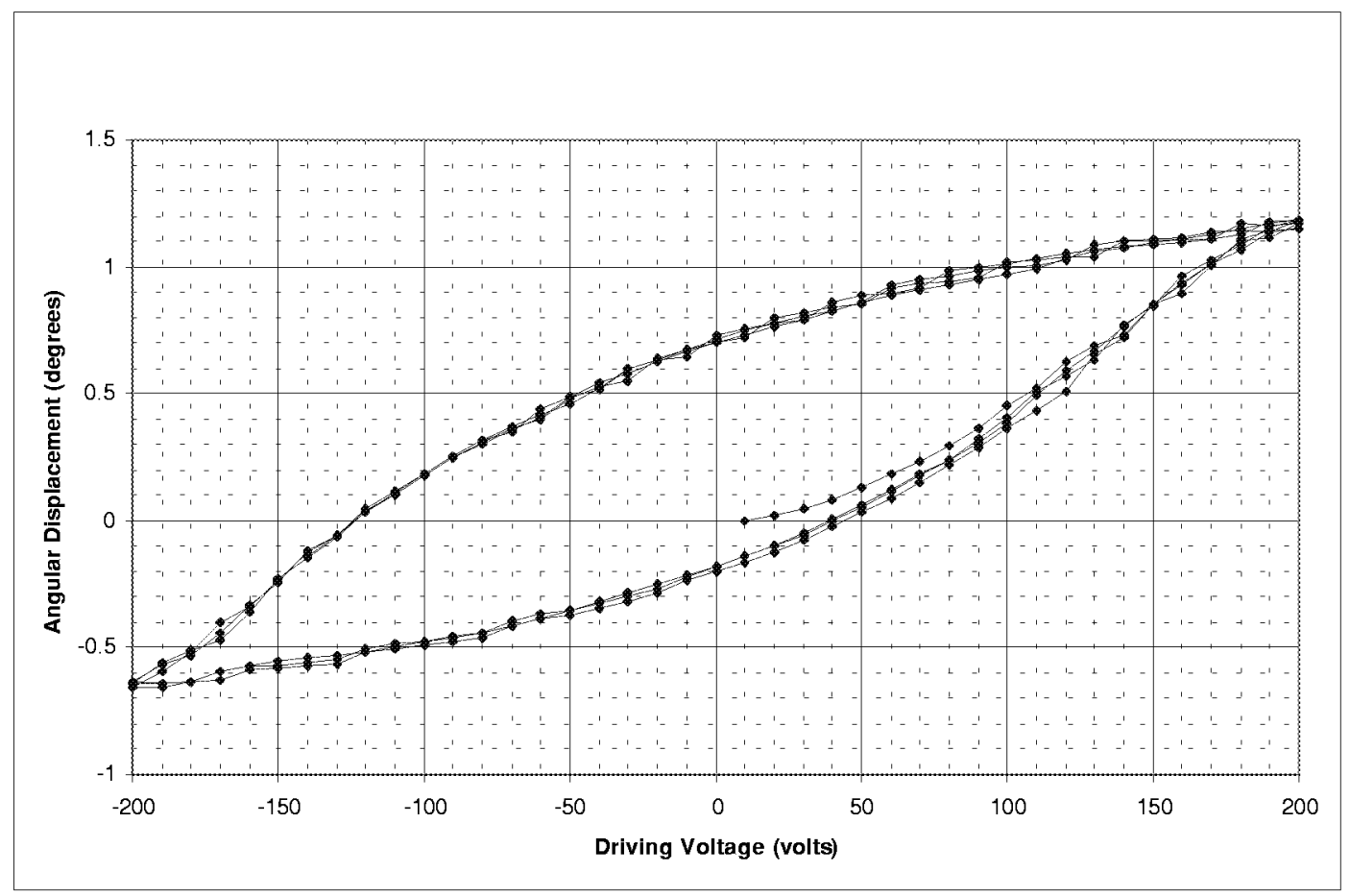

Figure 6: Angular displacement as a function of applied voltage 


\section{ANALYSIS}

Various aspects of the analytical model generation and validation are discussed. Commercially available software tools were used. Results generated with the models are presented and compared with test data.

\subsection{Modeling Approach}

A NASTRAN $\AA^{2}$ non-linear finite element model was developed for predicting dome heights resulting from fabrication and applied voltages to the PZT layer. The finite element model assumes that all layers are bonded at the glass transition temperature of LARC ${ }^{\text {TM }}$-SI (assumed to be 250 degrees $\mathrm{C}$ ). The bonding constrains all layers to move together while the specimen is cooled, generating thermal stresses due to differing CTEs in the layers. This bonding was modeled by attaching the layers together using rigid bars. Since thermal load equivalent to voltage was applied to PZT layer the nodes that are connect to rigid bars on the PZT layer are set to be independent. This will allow the PZT layer to be the driving layer during straining due to thermal load. The model only accounts for the process when the device was cooled from 250 degrees $\mathrm{C}$ to room temperature (25 degrees $\mathrm{C}$ ).

The modeling effort is divided into two parts; the first part models the cooling process from the glass transition temperature to room temperature where the initial doming occurs. The thermal strain resulting from the cooling is

$$
\varepsilon_{\text {thermal }}=\alpha \Delta T
$$

where $\varepsilon_{\text {thermal }}$ is the thermal strain due to the cooling process $\alpha$ is the average coefficient of thermal expansion of all layers calculated by NASTRAN®, and $\Delta T$ is the temperature difference.

The second part models the strain resulting from the applied voltage,

$$
\varepsilon_{\text {piezo }}=d_{31} \frac{V}{t_{p z t}}
$$

where $\varepsilon_{\text {piezo }}$ is the piezoelectric strain, $\mathrm{d}_{31}$ is the piezoelectric charge constant, $V$ is the applied voltage, and $t_{p z t}$ is the thickness of the PZT layer.

To incorporate the voltage effects into the NASTRAN® model, a simple thermal analogy was used. The total strain due to voltages as well as initial cooling was determined as follows

$$
\varepsilon_{\text {total }}=\varepsilon_{\text {thermal }}+\varepsilon_{\text {piezo }}
$$

\subsection{Model description}

The model was developed and using I-DEAS $\mathbb{B}^{3}$ Master Series Version 6.0. A mid-surface was created on each layer. After meshing was completed, the mid-surfaces were connected using rigid bars as shown in Figure 7.

The NASTRAN® model was constructed using 4 layers of stainless steel, polyimide, PZT 5A, and polyimide. The material properties for each layer are shown in Table 1. The finite element model has 160 CQUAD4 quadrilateral plate elements, 164 rigid elements (RBAR's), 220 nodes, and 1100 degrees-of-freedom. The boundary conditions for the model are pinned at one end and guided at the other end. Since the device exhibits geometric non-linearity due to large displacements, SOL 106 was used in NASTRAN@ for non-linear static thermal analysis. To assure convergence, the temperature range was divided into ten segments. Although rigid bar elements are not recommended for use in non-linear analysis of systems undergoing large deformations, the observed element deformation is small and the associated error is negligible. Based on the manufacturers' data ${ }^{4}$, a value of $\mathrm{d}_{31}=-6.9 \times 10^{-9}$ inches/volt, was used. 


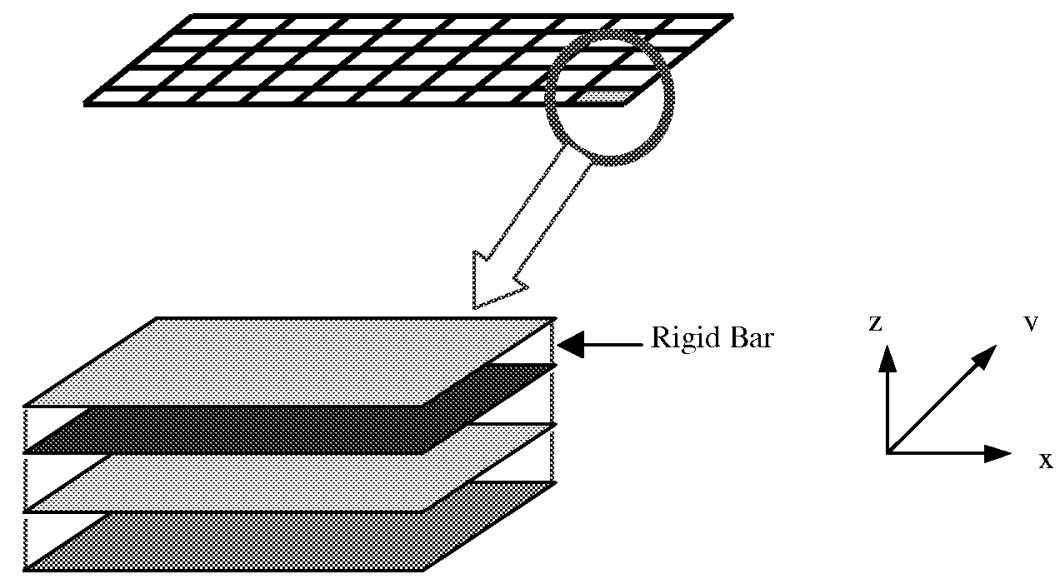

Figure 7. Sketch of lay-up construction using rigid bars

The assumption was made that at 250 degrees $C$ the layers are bonded and consolidated. Therefore, the cooling process was modeled from 250 degrees $C$ to 25 degrees $C$. RBAR elements were used to model this bonding. Since RBAR's connected two layers together, there exist independent and dependent degrees of freedom nodes on each layer. The nodes on the PZT mid-layer had the independent degrees of freedom, and all the nodes on other layers had the dependent degrees of freedom. TEMP (INIT) and TEMP (LOAD) NASTRAN® commands were used to assign initial and final temperature loads to TEMPD cards. The analysis included two subcases: The initial analysis modeled the fabrication cooling process; the second kept all of the grid points at room temperature, while voltages (as equivalent temperatures) were added to nodes on the PZT layer. Upon completion of the NASTRAN ${ }^{\circledR}$ analysis, the results were exported to I-DEAS ${ }^{\circledR}$ for graphical presentation.

\begin{tabular}{|c|c|c|c|c|}
\hline & Material & $\begin{array}{c}\text { Thickness } \\
\text { (in.) }\end{array}$ & $\begin{array}{c}\text { Modulus of } \\
\text { Elasticity (E) } \\
\text { (psi) } \times 10^{6}\end{array}$ & $\begin{array}{c}\text { Coefficient of } \\
\text { Thermal Expansion } \\
\text { (CTE) } 10^{-6} /{ }^{0} \mathrm{C}\end{array}$ \\
\hline Layer 1 & LARC'M-SI & 0.002 & 0.58 & 46 \\
\hline Layer 2 & PZT 5A & 0.008 & 9 & 1.5 \\
\hline Layer 3 & LARC-SI & 0.002 & 0.58 & 46 \\
\hline Layer 4 (Bottom layer) & Stainless Steel & $\mathbf{0 . 0 0 2}$ & 38 & 17.3 \\
\hline
\end{tabular}

Table 1: Lay-ups and Material Properties used in NASTRAN Non-linear model

\subsection{Analysis results}

As shown in Figure 8 the rotational angle of the center nodes about the y-axis represented the rotational angle of the gimbal. Since the rotation was extremely small, the displacements in the $\mathrm{z}$ direction of nodes located on both sides of the center nodes were used to verify the gimbal rotation angle. The calculated peak angle for the center node was 0.81 degrees whereas the nominal experimental result was 0.91 degrees. Figure 9 shows a plot of the rotational angles as a function of applied voltage for the center nodes. 


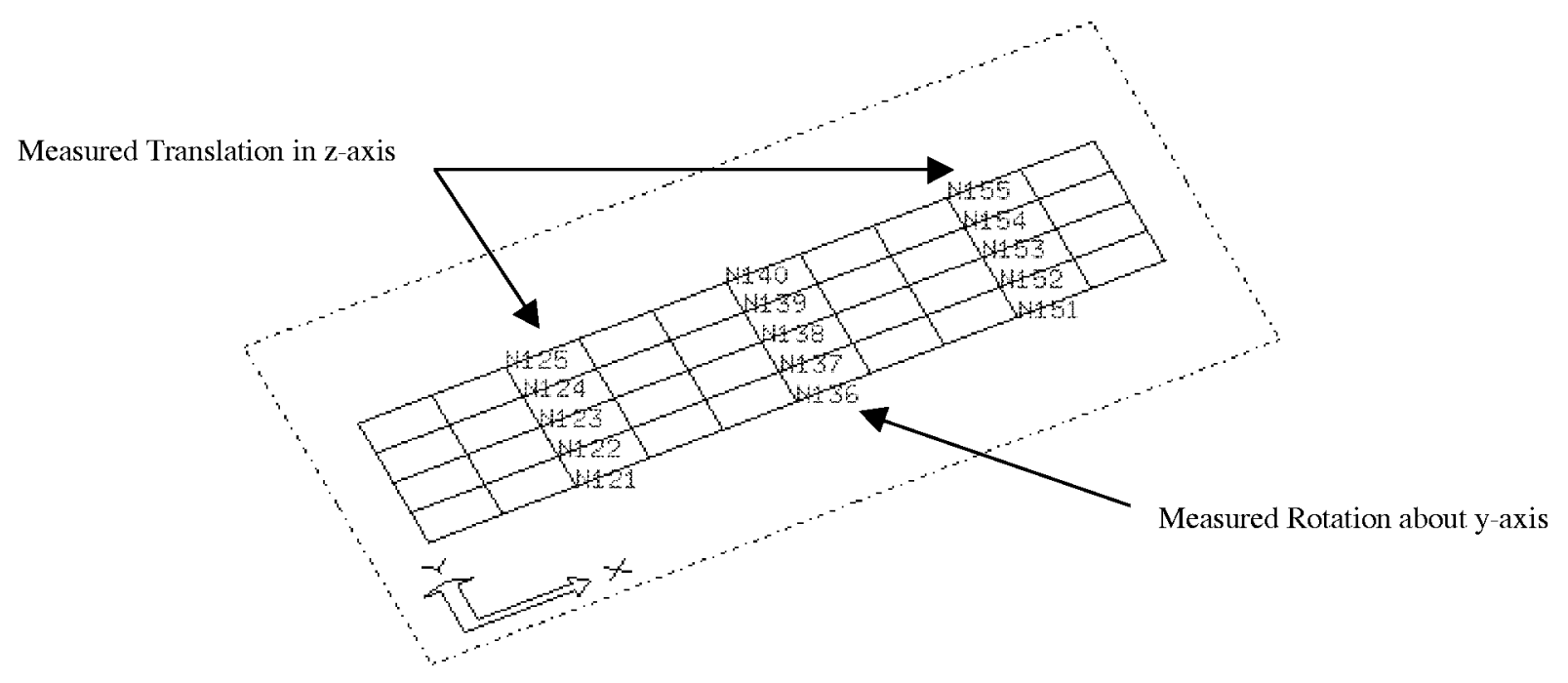

Figure 8: Nodes with measured rotational and translational degrees of freedom

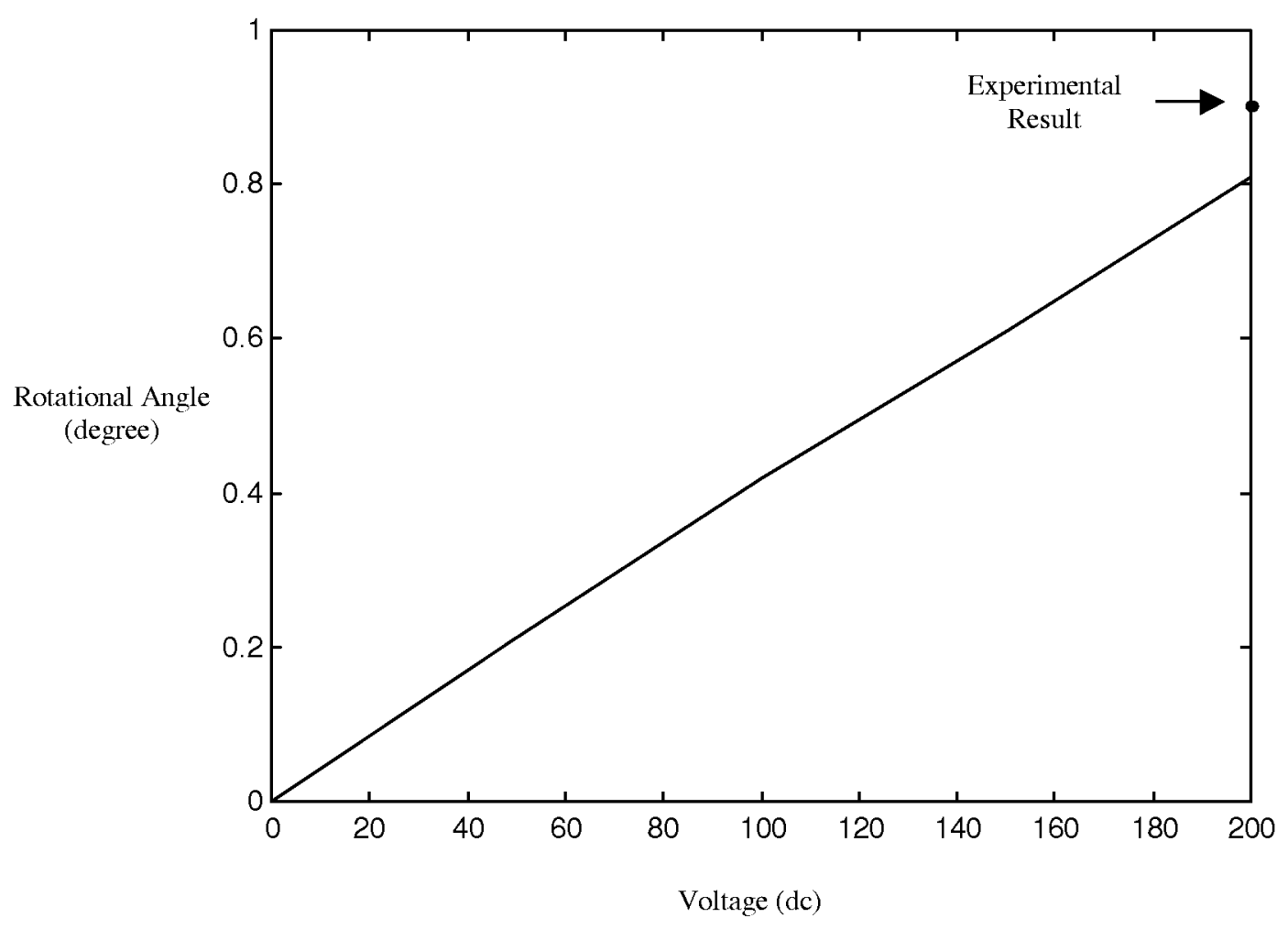

Figure 9: Rotation at the center nodes as a function of input voltage 


\section{ANALYSIS VS. TEST RESULTS}

From the results in Figure 9, the relationship between the rotational angle and the input voltages is almost linear. This conclusion applies to both positive and negative voltages. Results are shown in Figure 9 for positive voltages only. The analysis predicted a gimbal angle of \pm 0.81 degrees for a driving voltage of \pm 200 volts. The experimental measurement of the gimbal angle is approximately \pm 0.91 degree for \pm 200 volts. In general, the analytical model is stiffer than the actual hardware. Several factors contribute to this discrepancy. First, the polypropylene support has a non-ideal hinge at both ends that support the curved piezoceramic composite. This non-ideal hinge has friction and stiffness, which are not included in the model. Secondly, the actual piezoceramic composite is thicker than the FEM at several locations because of the thickness of the electrical leads. Thirdly, the FEM does not model the material damping that gives rise to the hysteresis loop in the actual response data. Finally, a key factor in the difference between analysis test is the value of $d_{31}$. There have been numerous references dealing with the relationship between piezoelectric constant $d_{31}$ and stress. Jaffe, Cook and Jaffe ${ }^{5}$ show plots where stress causes a change in $\mathrm{d}_{31}$ of a factor of two. Since THUNDER actuators are unimorph and exhibit curving, any change in curvature causes a change in stress, which in turn causes a change in $d_{31}$. The piezoelectric constant that was used for this analysis was based on the manufacturer's data. However, since there is so much uncertainty in the value of $\mathrm{d}_{31}$, a sensitivity study was conducted to determine the effect of $d_{31}$ on rotation. Rotational angles were plotted against piezoelectric constant as seen in Figure 10. Recall, the value used for $d_{31}$ was $-6.9 \times 10^{-9}$ in/Volt. The value of $d_{31}$ which yielded the experimental result was $\mathrm{d}_{31}=-7.8 \times 10^{-9}$ in/Volt.

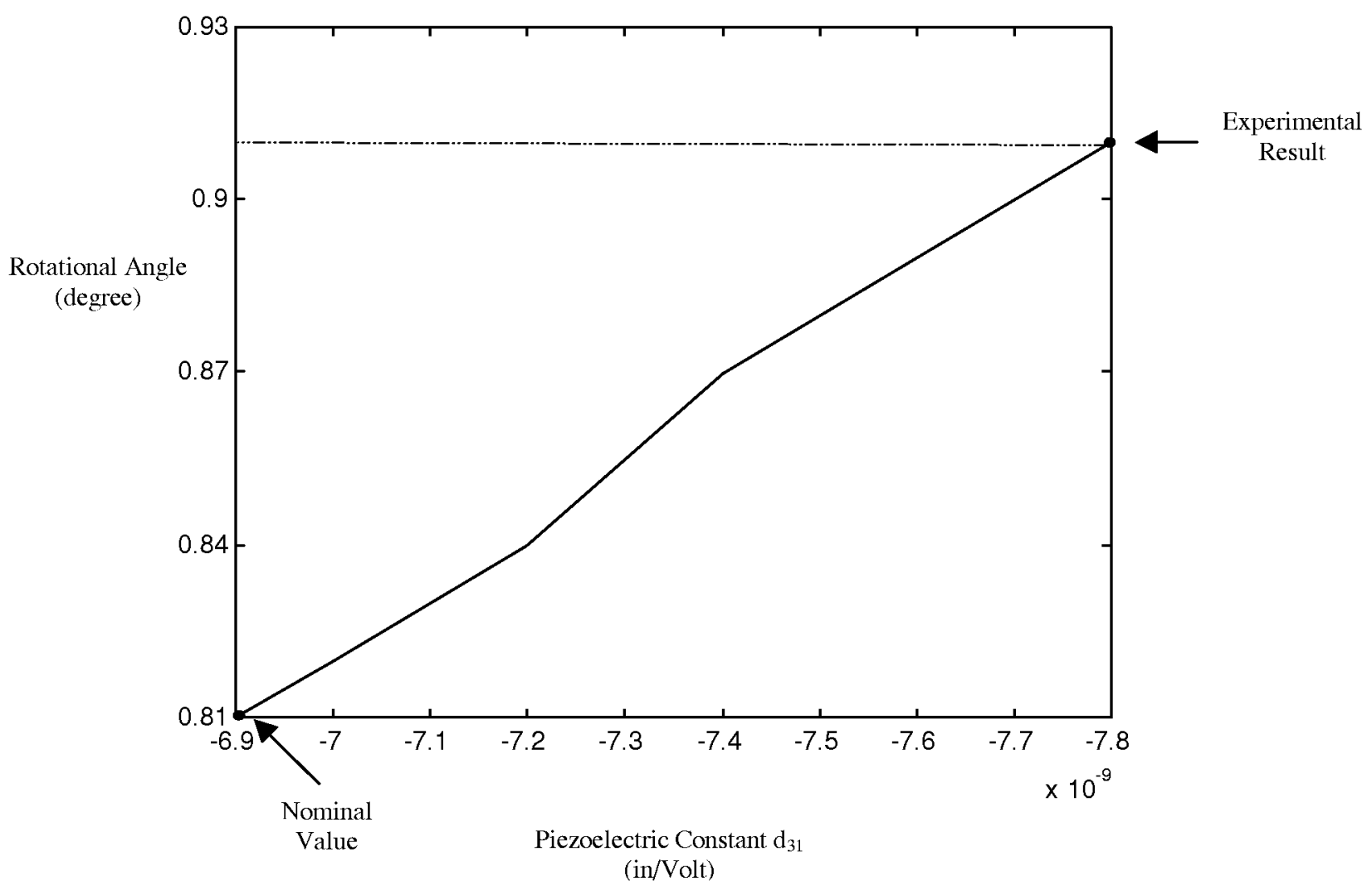

Figure 10: Plot of rotational angles as a function of piezoelectric constant $d_{31}$ 


\section{CONCLUDING REMARKS}

This paper describes the fabrication, testing, and analysis of a single axis piezoceramic gimbal. The fabrication process consists of pre-stressing a piezoceramic wafer using a high-temperature thermoplastic polyimide and a metal foil. The differential thermal expansion between the ceramic and metal induces a curvature. The piezoceramic is mounted on a support mechanism and a mirror is attached to the piezoceramic. A finite element model of the piezoceramic gimbal was used to predict gimbal behavior. The difference between calculated and measured analyses was about 11 percent. A sensitivity study on the piezoelectric charge constant $d_{31}$ (which was an uncertain input value to the analysis) was performed. This sensitivity study indicated that given a small error in this value had a large effect on the analytical results.

The feasibility of the gimbal as a high frequency scanner has been demonstrated. In general, piezoceramics can achieve high frequency response and it is anticipated that this scanner will, also. The piezoceramic gimbal is simple, inexpensive to manufacture, has no parts to wear out, and is lightweight.

\section{ACKNOWLEDGEMENTS}

The authors wish to thank Mr. Ruben Remus of NASA Langley for his work with the data acquisition system and Messrs. John Teter, Eugene Robbins, and Ben Copeland of NASA Langley for the design and fabrication of the piezoceramic gimbal.

\section{REFERENCES}

1. K. M. Mossi, G. V. Selby, and R. G. Bryant, "Thin-layer Composite Unimorph ferroelectric driver and sensor properties." Materials Letters, 35 (1998) 39-49.

2. L. H. Sang, MSC / NASTRAN Handbook for Non-Linear analysis, The MacNeil Schwendler Corporation, 1992.

3. I-DEAS@ Simulation User’s Guide, Structural Dynamics Research Corporation, 1996.

4. Morgan Matroc Inc. Product Handbook.

5. Jaffe, B., Cook, W. R., and Jaffe, H., Piezoelectric Ceramics, Academic Press, New York, 1971. 


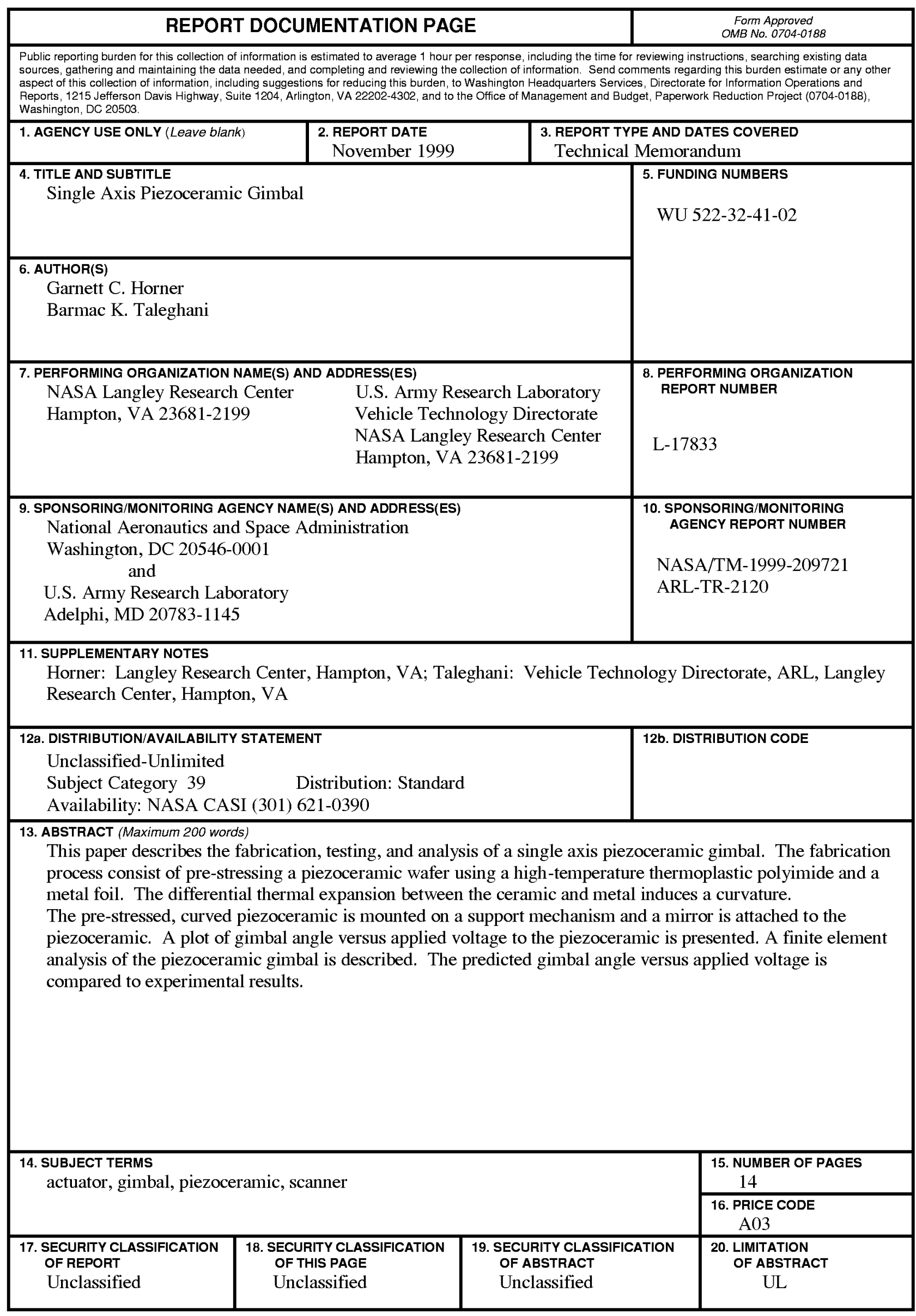

